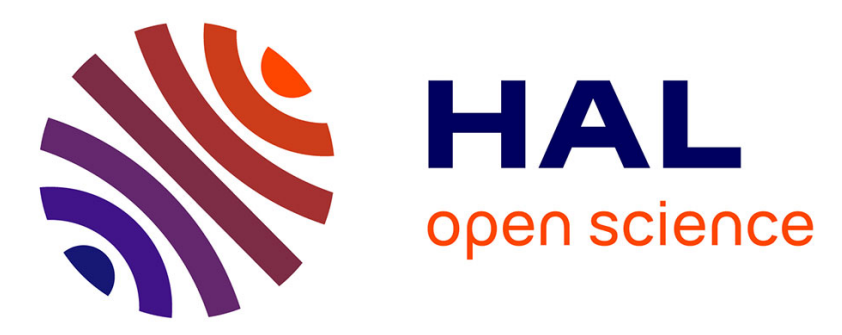

\title{
GENETIC VARIABILITY OF TMPRSS6 GENE AND ITS ASSOCIATION WITH IRON DEFICIENCY ANAEMIA
}

Paola Delbini, Valentina Vaja, Giovanna Graziadei, Lorena Duca, Isabella Nava, Chiara Refaldi, Maria Domenica Cappellini

\section{To cite this version:}

Paola Delbini, Valentina Vaja, Giovanna Graziadei, Lorena Duca, Isabella Nava, et al.. GENETIC VARIABILITY OF TMPRSS6 GENE AND ITS ASSOCIATION WITH IRON DEFICIENCY ANAEMIA. British Journal of Haematology, 2010, 151 (3), pp.281. 10.1111/j.13652141.2010.08349.x . hal-00569411

\section{HAL Id: hal-00569411 https://hal.science/hal-00569411}

Submitted on 25 Feb 2011

HAL is a multi-disciplinary open access archive for the deposit and dissemination of scientific research documents, whether they are published or not. The documents may come from teaching and research institutions in France or abroad, or from public or private research centers.
L'archive ouverte pluridisciplinaire HAL, est destinée au dépôt et à la diffusion de documents scientifiques de niveau recherche, publiés ou non, émanant des établissements d'enseignement et de recherche français ou étrangers, des laboratoires publics ou privés. 


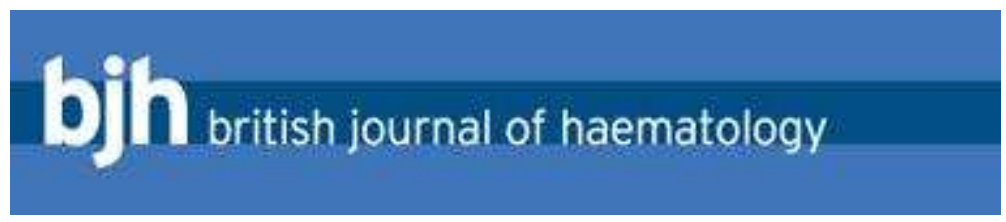

\section{GENETIC VARIABILITY OF TMPRSS6 GENE AND ITS ASSOCIATION WITH IRON DEFICIENCY ANAEMIA}

\begin{tabular}{|r|l|}
\hline Journal: & British Journal of Haematology \\
\hline Manuscript ID: & BJH-2010-00720.R1 \\
\hline Manuscript Type: & Short Reports \\
\hline Author: & 25-Jun-2010 \\
\hline Complete List of Authors: & $\begin{array}{l}\text { Delbini, Paola; Fondazione IRCCS "Ca' Granda"-Ospedale Maggiore } \\
\text { Policlinico,University of Milan, Internal Medicine } \\
\text { Vaja, Valentina; Fondazione IRCCS "Ca' Granda"-Ospedale } \\
\text { Maggiore Policlinico,University of Milan, Internal Medicine } \\
\text { Graziadei, Giovanna; Fondazione IRCCS "Ca' Granda"-Ospedale } \\
\text { Maggiore Policlinico,University of Milan, Internal Medicine } \\
\text { Duca, Lorena; Fondazione IRCCS "Ca' Granda"-Ospedale Maggiore } \\
\text { Policlinico,University of Milan, Internal Medicine } \\
\text { Nava, Isabella; Fondazione IRCCS "Ca' Granda"-Ospedale Maggiore } \\
\text { Policlinico,University of Milan, Internal Medicine } \\
\text { Refaldi, Chiara; Fondazione IRCCS "Ca' Granda"-Ospedale Maggiore } \\
\text { Policlinico,University of Milan, Internal Medicine } \\
\text { Cappellini, Maria Domenica; Fondazione IRCCS "Ca' Granda"- } \\
\text { Ospedale Maggiore Policlinico,University of Milan, Internal Medicine }\end{array}$ \\
\hline Key Words: & \begin{tabular}{l} 
IRON, ANAEMIA, TMPRSS6, IRIDA, haplotype \\
\hline \hline
\end{tabular} \\
\hline \hline
\end{tabular}

\section{ScholarONE}




\section{GENETIC VARIABILITY OF TMPRSS6 GENE AND ITS ASSOCIATION WITH IRON DEFICIENCY ANAEMIA}

Paola Delbini, Valentina Vaja, Giovanna Graziadei, Lorena Duca, Isabella Nava, Chiara Refaldi, Maria Domenica Cappellini

Fondazione IRCCS "Ca' Granda"-Ospedale Maggiore Policlinico,University of Milan, Milan, Italy

Short running Title

TMPRSS6 gene variability in iron deficiency anaemia

\section{Corrispondence:}

Prof. Maria Domenica Cappellini, Fondazione IRCCS "Ca' Granda" - Ospedale Maggiore

Policlinico, Via F. Sforza 35, 20122, University of Milan, Milan, Italy;

Phone: +39 0255033358, Fax: +39 0250320296, E-mail: maria.cappellini@unimi.it 


\begin{abstract}
Summary
Transmembrane Protease, Serine 6 (TMPRSS6) has an important role in iron homeostasis and its mutations, performed in TMPRSS6-deficient mice, have been recently associated with iron-refractory iron deficiency anaemia (IRIDA). Several variants of TMPRSS6 have been already identified; however the role of polymorphisms and TMPRSS6 haplotypes, causing iron deficiency anaemia, have not yet been investigated. In this study TMPRSS6 gene was sequenced in 16 subjects with IRIDA phenotype. We identified twenty-seven DNA polymorphisms. Eight SNPs and four haplotypes were significantly associated with ironrefractory anaemia $(p<0.001)$. Our preliminary results suggest a possible association between specific haplotypes of TMPRSS6 gene and IRIDA.
\end{abstract}

Keywords: TMPRSS6, anaemia, iron, IRIDA, haplotype

Iron deficiency anaemia is usually an acquired condition attributed to poor iron dietary intake or chronic blood loss. However, previous studies have described a familial syndrome characterized by iron deficiency anaemia not responding to oral iron and responding only partly to parenteral iron (Hartman et al, 1996; Pearson et al, 1999). This condition, named iron-refractory iron deficiency anaemia (IRIDA) is an autosomal recessive disease characterised by congenital hypochromic, microcytic anaemia, very low mean corpuscular volume, low transferrin saturation and normal/low ferritin. IRIDA has recently been shown to be caused by mutations in the TMPRSS6 gene, which encodes a type II transmembrane serine protease, matriptase-2, that is predominantly expressed in the liver (Finberg et al, 2008; Melis et al, 2008). Recent studies performed in TMPRSS6-deficient mouse model and in cell cultures have shown that matriptase- 2 functions as a negative regulator of hepcidin expression ( $\mathrm{Du}$ et al, 2008; Folgueras et al, 2008). Matriptase-2 represses hepcidin 


\section{Materials and methods}

Study subjects

\section{Sixteen adult individuals, evocative for IRIDA, showed anaemia of varying severity} $(\mathrm{Hb}=9.3 \pm 1.5 \mathrm{~g} / \mathrm{dL})$, severe microcytosis $(\mathrm{MCV}=64.2 \pm 8.8 \mathrm{fl})$, low serum iron $\underline{(63.2 \pm 23.3} \mathbf{\mu g} / \mathbf{d L})$, low transferrin saturation $(\mathrm{TS}=15.9 \pm 6.2 \%)$, and low serum ferritin $(9.8 \pm 4.5 \mathrm{ng} / \mathrm{mL})$. Specific tests (antigliadin antibodies, anti-transglutaminase antibodies, stool test for occult blood and endoscopy tests) excluded other causes of iron-deficiency anaemia, such as malabsorption and bleeding. Thalassaemia, sideroblastic anaemia and the common forms of congenital dyserythropoietic anaemias were excluded. DMT1 gene mutations were excluded by direct sequencing. Oral iron treatment had no effect on reticulocytes and $\mathrm{Hb}$, while intravenous iron produced a minimal response. The control population consisted of 35 non-anaemic men and 15 menstruating nonanaemic women with serum ferritin levels $>20 \mathrm{ng} / \mathrm{ml}$ and serum transferrin saturations $>15 \%$. Written informed consent for genetic analysis was obtained from the 16 subjects, who were identified among subjects presenting at outpatients source of the Hereditary Anaemia Center of Fondazione IRCCS "Ca' Granda"-Ospedale Maggiore Policlinico, because of their anaemia. 
The study protocol was approved by the hospital ethic committee of Fondazione IRCCS "Ca' Granda"-Ospedale Maggiore Policlinico in Milan and was performed according to the tenets of the Declaration of Helsinki.

\author{
Analysis of the TMPRSS6 DNA sequence
}

Genomic DNA was isolated from peripheral blood lymphocytes and sequence variations in TMPRSS6 gene were evaluated by polymerase chain reaction (PCR) and direct sequencing. Direct sequencing was performed using a fluorescence-tagged dideoxy chain terminator method in an ABI BigDye Terminator v3.1 Cycle Sequencing Kit (Applied Biosystems, Foster City, CA, USA), according to the manufacturer's instructions.

\title{
Statistical analysis
}

Fisher's exact tests were used to test the allelic and genotypic associations of all the SNPs with iron deficiency anemia. Hardy-Weinberg equilibrium (HWE) of the genotypic frequencies among cases and controls was examined. To determine statistically significant differences in genotype and allele frequencies between the two groups, the $\chi 2$ test or Fisher's exact test for the $2 \times 2$ contingency table file was used. The strength of the association was estimated by odds ratio of risk (OR) and $95 \%$ confidence intervals (CI). Linkage disequilibrium (LD) calculations were done using the Haploview package. Haplotype frequency estimation and association analysis using the permutation test were performed with Haploview version 4.0 software (Broad Institute of MIT and Harvard, Cambridge, MA, USA). Haplotype distributions were evaluated by the permutation test on the basis of 10,000 replications to obtain the empirical significance (Barrett et al, 2005). A cut off criterion of $\mathrm{p}<0.01$ for a significance test on the contingency table of all possible simulated haplotypes within possible SNP combination in cases and controls was used. 


\section{Results and Discussion}

Complete sequencing of TMPRSS6 gene (Reference Sequence NM_153609) from 16 subjects with iron deficiency anaemia was performed. Two novel single nucleotide substitutions were found in two unrelated IRIDA subjects: $n t .35801185 \mathrm{~A}>\mathrm{G}$ which predicts the amino acid substitution H448R and nt.35829153C $>\mathrm{T}$ which predicts a synonymous change F5F. Coding coordinates for both nucleotides and amino acids are numbered from the start of translation. Two rare known nonsynonymous polymorphisms, nt.35815670A $>\mathrm{G}$ (rs2235324) and nt.35793530G>A (rs2235979) were found in different subjects. Twenty-seven different DNA polymorphisms, eight of which are novel, were identified. Sixteen different DNA sequence variations were identified in controls. None of these sequence variations was novel. The distribution of the allele frequencies for SNPs are shown in Fig.1. The overall genotype call rate was 95\% (range, 92-96\%), and the accuracy was $100 \%$ according to duplicate genotyping of $>5 \%$ of samples. Significant deviation from HWE was observed in controls for three SNPs, rs5756515, rs5756516 and rs4824454. The use of high stringency cutoffs resulted in the loss of some genotyping data and reduction in the number of patients studied from the original sample set. Other SNPs evaluated in the final analysis were in HWE in controls, they had high call rates and concordant duplicates by genotyping, suggesting that this study was not likely to be influenced by genotyping errors. In the screen of twenty-seven SNPs of TMPRSS6, allele frequencies of rs855791C and rs2235321T, already reported in LD (Benyamin et al, 2009; Tanaka et al, 2010), were significantly increased in subjects with iron deficiency anaemia compared with healthy controls $(\mathrm{p}<0.0001, \mathrm{OR}=5.18,95 \%$ CI $2.21<12.11$ and $\mathrm{p}=0.011$, $\mathrm{OR}=3.33$, 95\%CI $1.27<8.71$, respectively). These TMPRSS6 SNPs are missense (rs855791) and synonymous (rs2235321) SNPs within the trypsin-like serine protease domain. Comparison with other serine proteases showed that the amino acid altered by rs 855791 is located close to both the catalytic and the specificity site of the serine protease, suggesting that rs 855791 may be a causal variant, acting through altered protease activity or substrate binding. The rs2235321, on exon 17 , was in LD with rs855791 ( $\left.\mathrm{D}^{\prime}=1.0, \mathrm{r}^{2}=0.444, \mathrm{CI}=0.8-1.0\right)$, representing probably the same signal. 
Among the common non-synonymous polymorphisms, rs11704654, rs4820268 and rs2543519 were most significantly associated with iron-refractory anaemia $(p<0.0001)$. However rs2543607 and rs2543633 were also associated with iron-refractory anaemia $(p<0.001, \mathrm{OR}=6.90,95 \% \mathrm{CI}$ $2.49<19.07)$ and in $\mathrm{LD}$ with each other $\left(\mathrm{D}^{\prime}=1.0, \mathrm{r}^{2}=0.211, \mathrm{CI}=0.73-1.0\right)$. The polymorphisms rs732733, rs732734 and rs2238761 were not significantly different between the groups $(\mathrm{p}=0.076)$, although a different trend was observed between anaemic and control subjects. A larger sample size is probably required considering our strict cut-off for significance.

To determine whether specific TMPRSS6 alleles might be associated with iron-refractory anaemia, and therefore overrepresented in the anaemic group, haplotypes and haplotype blocks within TMPRSS6 were derived using HaploView 4.0 software (http://www.broad.mit.edu/mpg /haploview) (Barrett et al, 2005). Based on the haplotype reconstruction results calculated by PHASE2.0, Haploview used the confidence interval method to perform LD assessment and defining of haplotype blocks. The $\mathrm{r}^{2}$ threshold for linkage disequilibrium was set at 0.8 and the multiple loci LOD threshold as 3.0. Only common haplotypes (frequency $>5 \%$ ) were retained in this study. In the haplotype analysis, we identified three haplotype block sets, containing 6, 9 and 2 SNPs respectively (Tab.1). Strong LD was observed within each block, meaning that each block is a smallest evolutionary unit. The CCCTTG, TCCTTG and CCCTCG haplotypes in Block 1 seemed to be risk haplotypes $(\mathrm{p}<0.0001, \mathrm{p}<0.001$ and $\mathrm{p}=0.0020$, respectively), while the CTCCCG haplotype was observed to be protective ( $\mathrm{p}=0.0052)$. In Block 2, the GGGGGCTTA haplotype was observed only in anaemic subjects $(0.085, \mathrm{p}=0.0033)$, while the AAAGATCTG haplotype was significantly less common in anaemic subjects $(0.094)$ than in control group $(0.385, \mathrm{p}<0.0020)$. Since the GGGGGCTTA haplotype was rare in all anaemic patients and absent in the controls, we think that the significant association between this haplotype and iron deficiency anaemia is not reliable. In Block 3 the predominant TMPRSS6 haplotype observed in subjects with iron deficiency anaemia was also the predominant haplotype observed among controls. 
The haematological and iron parameters of patients haplotype bloks, that show phenotype evocative for IRIDA, are reported in Table 2. Although we noted a significant association of these haplotypes with disease, none significant haematological differences among blocks were found. Our strict cut-off for significance indicates that it may require a much larger sample size to be confident of such an association. The low number of patients studied is one of the limitations of our study. Studies analyzing additional iron deficiency anaemia phenotypes in larger samples would enable us to confirm possible associations between the genetic TMPRSS6 polymorphisms and the iron deficiency anaemia phenotype.

In conclusion, our preliminary results suggest a possible association of genetic variants and specific haplotypes of TMPRSS6 gene with IRIDA. 


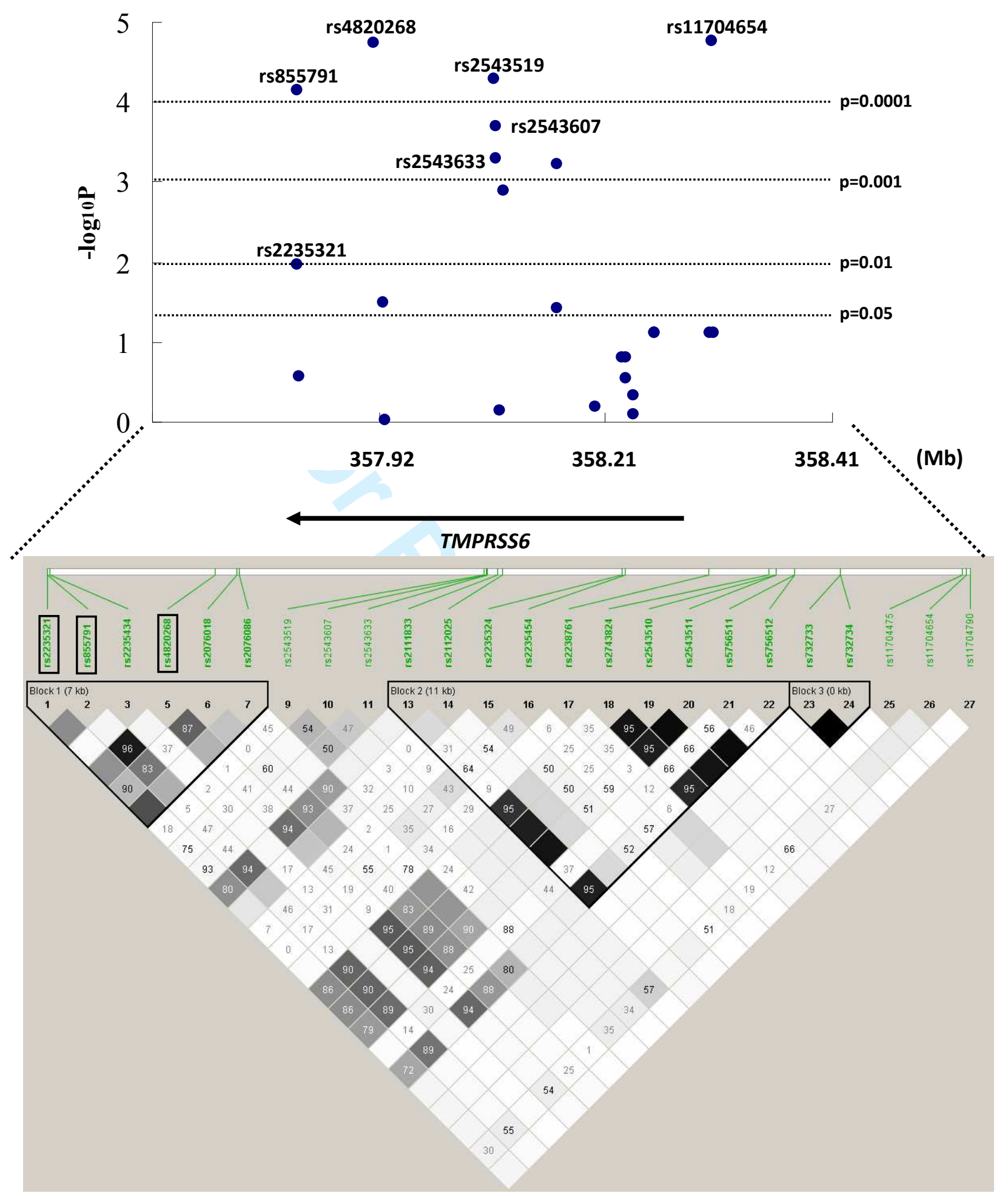

Fig 1. Linkage disequilibrium plot of the TMPRSS6 region and first screening of 24 tag single nucleotide polymorphisms (SNPs). In the upper panel, $P$ values for differences in allele frequencies were calculated by chi-square test using two-by-two contingency tables. The $-\log P$ value for each SNP is shown. In the lower panel, $r_{2}$ values calculated using Haploview version 4.0 software based on data from anaemic subjectscontrols cohort are shown. The location and direction of transcription of TMPRSS6 are indicated by arrows. 
Tab 1. Association analysis results based on haplotype blocks

\begin{tabular}{cccccc}
\hline Block & & $\begin{array}{c}\text { Haplotype } \\
\text { Frequency }\end{array}$ & Case, control ratios & $\chi \mathbf{~ 2}$ & p value \\
\hline \multirow{3}{*}{ Block 1 } & CTCCCG & 0.541 & $10.5: 21.5,61.0: 39.0$ & 7.821 & $<0.001$ \\
& CTCTTG & 0.092 & $2.1: 29.9,10.0: 90.0$ & 0.357 & n.s. \\
& CCCCTG & 0.061 & $0.0: 32.0,8.0: 92.0$ & 2.725 & n.s. \\
& CTTCCG & 0.056 & $0.5: 31.5,7.0: 93.0$ & 1.413 & n.s. \\
& CCCTTG & 0.045 & $6.0: 26.0,0.0: 100.0$ & 19.643 & $<0.0001$ \\
& TCCTTG & 0.033 & $4.4: 27.6,0.0: 100.0$ & 14.146 & $<0.001$ \\
& CCCTCG & 0.023 & $3.0: 29.0,0.0: 100.0$ & 9.593 & 0.0020 \\
& CCTCTG & 0.015 & $0.0: 32.0,2.0: 98.0$ & 0.65 & n.s. \\
& AAAGATCTG & 0.314 & $3.0: 29.0,38.5: 61.4$ & 9.563 & 0.0020 \\
& GAAGATCTG & 0.252 & $10.7: 21.3,22.6: 77.3$ & 1.516 & n.s. \\
& GAGGATCTG & 0.064 & $4.0: 28.0,4.5: 95.4$ & 2.581 & n.s. \\
& GAAAATCTG & 0.030 & $0.0: 32.0,4.0: 95.9$ & 1.319 & n.s. \\
& GGGGGCTTA & 0.021 & $2.7: 29.3,0.0: 99.9$ & 8.658 & 0.0033 \\
& Clock 3 & 0.992 & $31.0: 1.0,100.0: 0.0$ & 3.149 & n.s. \\
\hline
\end{tabular}


Tab 2. Haematological and Iron Parameters in patients haplotype blocks

\begin{tabular}{cccccc}
\hline Block & $\begin{array}{c}\text { Haemoglobin } \\
(\mathbf{g} / \mathbf{d L})\end{array}$ & $\begin{array}{c}\text { Mean Corpuscolar } \\
\text { Volume }(\mathbf{f L})\end{array}$ & $\begin{array}{c}\text { Serum Ferritin } \\
(\mathbf{n g} / \mathbf{m L})\end{array}$ & $\begin{array}{c}\text { Serum Iron } \\
(\boldsymbol{\mu g} / \mathbf{d L})\end{array}$ & $\begin{array}{c}\text { Transferrin } \\
\text { Saturation \% }\end{array}$ \\
\hline Block 1 & $9.5 \pm 1.5$ & $58.9 \pm 6.3$ & $9 \pm 5$ & $49 \pm 20$ & $14 \pm 11$ \\
Block 2 & $10.1 \pm 1.2$ & $61.0 \pm 8.1$ & $10 \pm 4$ & $50 \pm 21$ & $15 \pm 10$ \\
Block 3 & $9.5 \pm 1.7$ & $59.5 \pm 5.9$ & $9 \underline{4}$ & $49 \pm 20$ & $14 \pm 11$ \\
\hline
\end{tabular}

(values expressed as mean \pm standard deviation) 


\section{References}

Babitt, J.L., Huang, F.W., Wrighting, D.M., Xia, Y., Sidis, Y., Samad, T.A., Campagna, J.A., Chung, R.T., Schneyer, A.L., Woolf, C.J., Andrews, N.C., Lin, H.Y. (2006) Bone morphogenetic protein signaling by hemojuvelin regulates hepcidin expression. Nature Genetics, 38, 531-539.

Barrett, J.C., Fry, B., Maller, J., Daly, M.J. (2005) Haploview: analysis and visualization of LD and haplotype maps. Bioinformatics, 21, 263-265.

Benyamin, B., Ferreira, M.A.R, Willemsen, G., Gordon, S., Middelberg, R.P.S., McEvoy, B.P., Hottenga, J., Henders, A.K., Campbell, M.J., Wallace, L., Frazer, I.H., Heath, A.C., de Geus, E.J.C., Nyholt, D.R., Visscher, P.M., Penninx, B.W., Boomsma, D.I., Martin, N.G., Montgomery, G.W. \& Whitfield, J.B. (2009) Common variants in TMPRSS6 are associated with iron status and erythrocyte volume. American Journal of Human Genetics, 84, 60-65.

Chambers, J.C., Zhang, W., Li, Y., Sehmi, J., Wass, M.N., Zabaneh, D., Hoggart, C., Bayele, H., McCarthy, M.I., Peltonen, L., Freimer, N.B., Srai, S.H., Maxwell, P.H., Sternberg, M.J.E., Ruokonen, A., Abecasis, G., Jarvelin M., Scott, J., Elliott P. \& Kooner J.S. (2009) Genome-wide association study identifies variants in TMPRSS6 a ssociated with hemoglobin levels. Nature Genetics, 41, 1170-1172.

Du, X., She, E., Gelbart, T., Truksa, J., Lee, P., Xia, Y., Khovananth, K., Mudd, S., Mann, N., Moresco, E.M.Y., Beutler, E., Beutler B. (2008) The serine protease TMPRSS6 is required to sense iron deficiency. Science, 320, 1088-1092.

Finberg, K.E., Heeney, M.M., Campagna, D.R., Aydinok, Y., Pearson, H.A., Hartman, K.R., Mayo, M.M., Samuel, S.M., Strouse, J.J., Markianos, K., Andrews, N.C. \& Fleming M.D. (2008) Mutations in TMPRSS6 cause iron-refractory iron deficiency anaemia (IRIDA). Nature Genetics, 40, 569-571. 
Folgueras, A.R., Martin de Lara, F., Pendas, A.M., Garabaya, C., Rodriguez, F., Astudillo, A., Bernal, T., Cabanillas, R., Lopez-Otin, C., and Velasco, G. (2008) The membrane-bound serine protease matriptase-2 (Tmprss6) is an essential regulator of iron homeostasis. Blood, 112, 25392545.

Hartman, K.R., Barker, J.A. (1996) Microcytic anemia with iron malabsorption: an inherited disorder of iron metabolism. American Journal of Hematology, 51, 269-275.

Melis, M.A., Cau, M., Congiu, R., Sole, G., Barella, S., Cao, A., Westerman, M., Cazzola, M. and Galanello R. (2008) A mutation in the TMPRSS6 gene, encoding a transmembrane serine protease that suppresses hepcidin production, in familial iron deficiency anaemia refractory to oral iron. Haematologica, 93, 1473-1479.

Pearson, H.A., Lukens, J.N. (1999) Ferrokinetics in the syndrome of familial hypoferremic microcytic anaemia with iron malabsorption. Journal of Pediatric Hematology/Oncology, 21, 412417.

Silvestri, L., Pagani, A., Nai, A., De Domenico, I., Kaplan, J., Camaschella, C. (2008) The serine protease matriptase-2 (TMPRSS6) inhibits hepcidin activation by cleaving membrane hemojuvelin. Cell Metabolism, 8, 502-511.

Tanaka, T., Roy, C.N., Yao, W., Matteini, A., Semba, R.D., Arking, D., Walston, J.D., Fried, L.P., Singleton, A., Guralnik, J., Abecasis, G.R., Bandinelli, S., Longo D.L. and Ferrucci L. (2010) A genome-wide association analysis of serum iron concentrations. Blood, 115, 94-96. 